\title{
MALIGNANT PHAEOCHROMOCYTOMA: CLINICAL, BIOCHEMICAL AND SCINTIGRAPHIC CHARACTERIZATION
}

\author{
B. SHAPIRO, J.C. SISSON, R. LLOYD, M. NAKAJO, \\ W. SATTER LEE AND W. H. BEIERWALTES. \\ Division of Nuclear Medicine Departments of Internal Medicine and Pathology $\dagger$ \\ University of Michigan Ann Arbor, Michigan 48109, USA
}

(Received 13 May 1983; revised 11 July 1983; accepted 14 July 1983)

\begin{abstract}
SUMMARY
We have evaluated thirty patients with malignant metastatic phaeochromocytoma with regard to clinical features, indices of catecholamine secretion, histology of lesions and a number of imaging procedures including scintigraphy with the recently developed sympathetic tissue-seeking radiopharmaceutical ${ }^{131}$ I-metaiodobenzylguanidine $\left({ }^{131} \mathrm{I}-\mathrm{MIBG}\right)$. The primary tumour was extraadrenal in 13 cases. The commonest site of metastases was the axial skeleton ( 20 cases), followed by liver (four cases), lymph nodes (four cases), peritoneum (two cases) and lung (three cases). The malignancies were indolent, the mean time following the initial diagnosis was 9.18 years (range 0 to 33 years) and the mean duration of known metastases 3.71 years (range 0 to 18 years). There was a wide range of abnormalities in plasma and urinary catecholamines which did not correlate with the extent of tumour spread, histological pattern (mitotic index, Zellballen pattern, capsular or vascular invasion pleomorphism or necrosis) or ${ }^{131} \mathrm{I}-\mathrm{MIBG}$ uptake by tumour deposits. ${ }^{131} \mathrm{I}-\mathrm{MIBG}$ scintigraphy was found to be a useful technique for determining the extent of metastatic disease in most cases (26 of 30 ) and in some patients ( 16 of 30 ) was more sensitive than other radiological procedures. No false positive scans were encountered.
\end{abstract}

Malignant phaeochromocytoma remains a disorder in which the diagnosis, management and prognosis are fraught with difficulty.

The prevalence of phaeochromocytoma has yet to be accurately defined but probably represents $0 \cdot 1-0.7 \%$ of the population having diastolic hypertension (Kvale et al., 1956; Gitlow et al., 1970; Manger \& Gifford, 1982), and a prevalence of $0 \cdot 09 \%$ has been reported in two large series of unselected autopsies (Minnow et al., 1954; Von Schlegle, 1960). The frequency of malignancy has been variously reported as $0 \%-19 \%$ (Sander et al., 1971; Mahoney \& Harrison, 1977), an average being approximately 10\% (Modlin et al., 1979; Scott et al., 1982). Some authors designate tumours with marked local invasiveness as

Correspondence: B. Shapiro, Division of Nuclear Medicine. Department of Internal Medicine, University of Michigan, Ann Arbor, Michigan 48109, USA. 
malignant (Bartles, 1959; Palmieri et al., 1961; Mahoney \& Harrison, 1977). However, the definition of malignancy for this tumour is difficult for it cannot be defined on histological criteria alone (Symington \& Goodall, 1953). The most rigorous definition of malignancy is that which requires that metastases should be present at a site where chromaffin tissue is not otherwise found, thus excluding the possibility of misclassifying multifocal primary lesions as metastases. The prognosis from a variety of reports of malignant phaeochromocytomas appears highly variable (Palmieri et al., 1961; James et al., 1972; Mahoney \& Harrison, 1977; Modlin et al., 1979).

We used ${ }^{131} \mathrm{I}$-metaiodobenzylguanidine $\left({ }^{131} \mathrm{I}-\mathrm{MIBG}\right)$ to portray the scintigraphic features of 30 patients having malignant phaeochromocytoma. The recently developed radiopharmaceutical, ${ }^{131}$ I-MIBG, structurally resembles noradrenaline and is taken up by phaeochromocytomas, by a mechanism believed to be similar to that by which noradrenaline is taken up following secretion (Wieland et al., 1980, 1981; Sisson et al., 1981). Thus, ${ }^{131} \mathrm{I}-\mathrm{MIBG}$ scintigraphy reflects an anatomical localization of a function specific to adrenergic tumours and therefore a new index of the nature and growth of phaeochromocytomas.

\section{MATERIALS AND METHODS}

The histological specimens of 20 of the 30 patients were reviewed. This included material from primary and in some cases metastatic tumours. Light microscopy was performed on haemotoxylin and eosin stained sections and in certain cases on Grimelius silver stained sections.

The plasma concentrations of norepinephrine, epinephrine and dopamine were determined in the fasted, supine and resting state by radioenzymatic assay (Peuler \& Johnson, 1977). The overnight (12-hour) urinary excretion of catecholamines and their metabolites was determined by the technique of Von Euler and Lishajko (1959).

${ }^{131}$ I-metaiodobenzylguanidine scintigraphy was performed by previously described techniques. The dose of $0.5 \mathrm{mCi}$ was administered by intravenous injection over $10-20 \mathrm{~s}$. The thyroidal uptake of the dissociated ${ }^{131}$ I-iodide was prevented by the administration of iodides. Multiple overlapping images including anterior and posterior views of the head, thorax, abdomen, pelvis and upper femoral regions were obtained (Sisson et al., 1981). Anatomical orientation was provided by surface markers and in selected cases by scintigraphic visualization of other organs such as kidney $\left.{ }^{99 \mathrm{~m}} \mathrm{Tc}-\mathrm{DTPA}\right)$, liver and spleen

Table 1. Results of ${ }^{131}$ l-MIBG scintigraphy compared to those of other radiological techniques*

$\begin{array}{lc}{ }^{131} \text { I-MIBG scintigraphy superior to other techniques } & 16 / 30 \\ { }^{131} \text { I-MIBG scintigraphy equal to other techniques } & 7 / 30 \\ { }^{131} \text { I-MIBG inferior to other techniques } & 7 / 30^{+}\end{array}$

* Other radiological techniques include various combinations of: chest $X$-ray, skeletal radiography, bone scan, intravenous pyelography, liver spleen scan. abdominal ultrasound, abdominal and or chest CT and angiography. All patients having had at least 3 of the 8 procedures.

+ Minimal or no ${ }^{131} \mathrm{I}-\mathrm{MIBG}$ uptake in three cases. Four patients had received external beam radiotherapy to principal tumour deposits. No false positive studies were encountered. 
( ${ }^{99 \mathrm{~m}} \mathrm{Tc}$-sulphur colloid), skeleton ( ${ }^{99 \mathrm{~m}} \mathrm{Tc}$-methylene diphosphonate (MDP), or heart $\left({ }^{201} \mathrm{~T} 1\right.$ or ${ }^{99 \mathrm{~m}} \mathrm{Tc}$-labelled red blood cells (RBCs). Digitized ${ }^{131} \mathrm{I}-\mathrm{MIBG}$ and orientation scans were superimposed by computer (Shapiro et al., 1982a).

A number of different modalities were used in various combinations to delineate the patients' lesions. They included standard radiographs, intravenous pyelography, ultrasound, computed tomography (CT), and arteriography in various combinations in different patients (see Table 1).

A total of thirty patients fulfilled the criteria for the diagnosis of malignant phaeochromocytoma (Palmieri et al., 1961). These patients were amongst the 270 patients referred to the University of Michigan Medical Center for ${ }^{131}$ I-metaiodobenzylguanidine ( ${ }^{131}$ I-MIBG) scintigraphy for known or suspected phaeochromocytomas between June 1980 and January 1983.

\section{RESULTS}

\section{Morphology}

In general, the light microscopic features of the tumours included a very vascular stroma with solid sheets of cells and a zellballen pattern. Hyaline droplets were frequently observed in the cytoplasm of most intra-adrenal tumours. Pleomorphism, mitotic figures, vascular and capsular invasion, and necrosis were frequently present; these features while not specific for malignancy occurred more frequently than in phaeochromocytomas that have classically been defined as benign. In most cases, the histologies of primary and metastatic lesions were similar; however, in two patients with skeletal metastases, the metastatic foci consisted of poorly differentiated spindle cells different from the primary neoplasm.

The histological features, and especially the invasive character, did not correlate with the anatomic extent of tumour spread. Moreover, the morphologies did not predict the uptake of ${ }^{131} \mathrm{I}-\mathrm{MIBG}$ on scintigraphy, or the hormone secretion determined by plasma catecholamine concentrations or urinary catecholamine excretion rates.

\section{Demographic features}

The majority of patients were male ( 21 of 30 ), the mean age at diagnosis was 32.0 years (range 10-57 years) with 11 of 30 occurring under the age of 18 years. The malignancies were indolent: mean duration following the initial diagnosis of phaeochromocytoma was $9 \cdot 18$ years (range $0-33$ years), while the mean duration of known metastases was 3.71 years (range $0-18$ years).

Two of the patients studied had definite historical, clinical or biochemical evidence for one of the neurocristopathic syndromes known to be associated with phaeochromocytoma, having Von Recklinghausen's neurofibromatosis and Von Hipple-Lindau's disease (Riccardi, 1981). Another had possible Von Hippel-Lindau's syndrome. Neurocristopathies not encountered were multiple endocrine neoplasia type 2A or 2B (Lorenzo, 1977; Sizemore et al., 1980). Two of the patients, however, gave a family history of phaeochromocytoma and one had a sister with 'nonfunctioning' paraganglioma resected; another case whose primary lesion arose from the bladder, gave the remarkable history of a mother who had two phaeochromocytomas resected from the pelvis and bladder as a teenager. 
In 13 of 30 cases the primary lesion was extra-adrenal (four para-renal, two bladder, two para-aortic, and one para-adrenal. pancreatic, left atrial, abdominal sympathetic chain and widespread).

\section{Functional indices}

\section{Hormone secretion}

Each patient had evidence for abnormally elevated secretion of catecholamines, but plasma noradrenaline concentrations varied widely from minimally abnormal (456 $\mathrm{pg} / \mathrm{ml})$ to markedly elevated $(54253 \mathrm{pg} / \mathrm{ml})$, the upper limit of normal being $350 \mathrm{pg} / \mathrm{ml}$. Plasma adrenaline concentrations were elevated in 18 of 30 cases to as high as $2834 \mathrm{pg} / \mathrm{ml}$ (upper limit of normal $100 \mathrm{pg} / \mathrm{ml}$ ). The urinary excretion rates of catecholamines and catecholamine metabolites were also variable and did not always correlate well with the plasma catecholamine concentrations. However, at least one fraction of the urinary excretion rates was abnormal in every case. The excretion rates of noradrenaline (range $35-10670 \mu \mathrm{g} / 12 \mathrm{~h}$; normal $<60 \mu \mathrm{g} / 12 \mathrm{~h}$ ) and VMA (range 2.5 to $56.5 \mathrm{mg} / 12 \mathrm{~h}$, normal $<3.5 \mathrm{mg} / 12 \mathrm{~h}$ ) had the highest diagnostic significance, each bcing elevated in all but two cases.

A particularly unusual pattern of excretion was observed in one patient who demonstrated normal or borderline levels for plasma catecholamine concentrations and for the urinary adrenaline, noradrenaline, metanephrine and VMA excretion rates, but in sharp contrast, his plasma concentration $(9200 \mathrm{pg} / \mathrm{ml}$, normal $<144 \mathrm{pg} / \mathrm{ml})$ and excretion rate of normetanephrine $(2664 \mu \mathrm{g} / 12 \mathrm{~h}$, normal $<82.5 \mu \mathrm{g} / 12 \mathrm{~h})$ were strikingly elevated. Although plasma dopamine concentrations were not measured in every case, there was no evidence that malignancy caused reversion to a more primitive type of secretion pattern in these phaeochromocytomas. Dopamine values were normal or near normal in each of the 10 instances where measured.

\section{${ }^{131}$ I-MIBG uptake and anatomic spread of tumour}

The extent of tumour dissemination was determined by ${ }^{131}$ I-MIBG scintigraphy and other medical imaging procedures and in some cases surgical exploration and the results are summarized in Table 1; representative examples are shown in Figs 1 to 4.

Skeletal metastases were present in 20 cases. ${ }^{131}$ I-MIBG scintigraphy revealed skeletal metastases in 19 of 30 cases. In 12 cases, ${ }^{99 m} \mathrm{Tc}-\mathrm{MDP}$ bone scans were performed; in six of these patients ${ }^{131}$ I-MIBG scintigraphy was more sensitive in establishing the extent of skeletal metastases ( $s i x$ patients) but in six cases the reverse was true. However, ${ }^{131}$ I-MIBG uptake may have been diminished by previous external beam irradiation directed at the skeletal metastases in four instances. Lesions occurred principally in the axial skeleton and varied from involvement of a single vertebral lesion to widespread dissemination, see Figs 1,2 and 3.

Hepatic metastases were present in four of 30 patients and concentrated ${ }^{131}$ I-MIBG to a moderate extent in three but not at all in one patient in whom CT and biopsy confirmed the lesions (see Fig. 3). Splenic involvement was observed in only one case. Primary tumours and tumours recurrent at the primary site also exhibited variable ${ }^{131}$ I-MIBG uptake: from excellent to barely detectable (Figs 1 and 4). Regional lymph node metastases were visualized in four patients but not in another in whom the deposits were microscopic and discovered only by histological study of nodes removed at operation. 

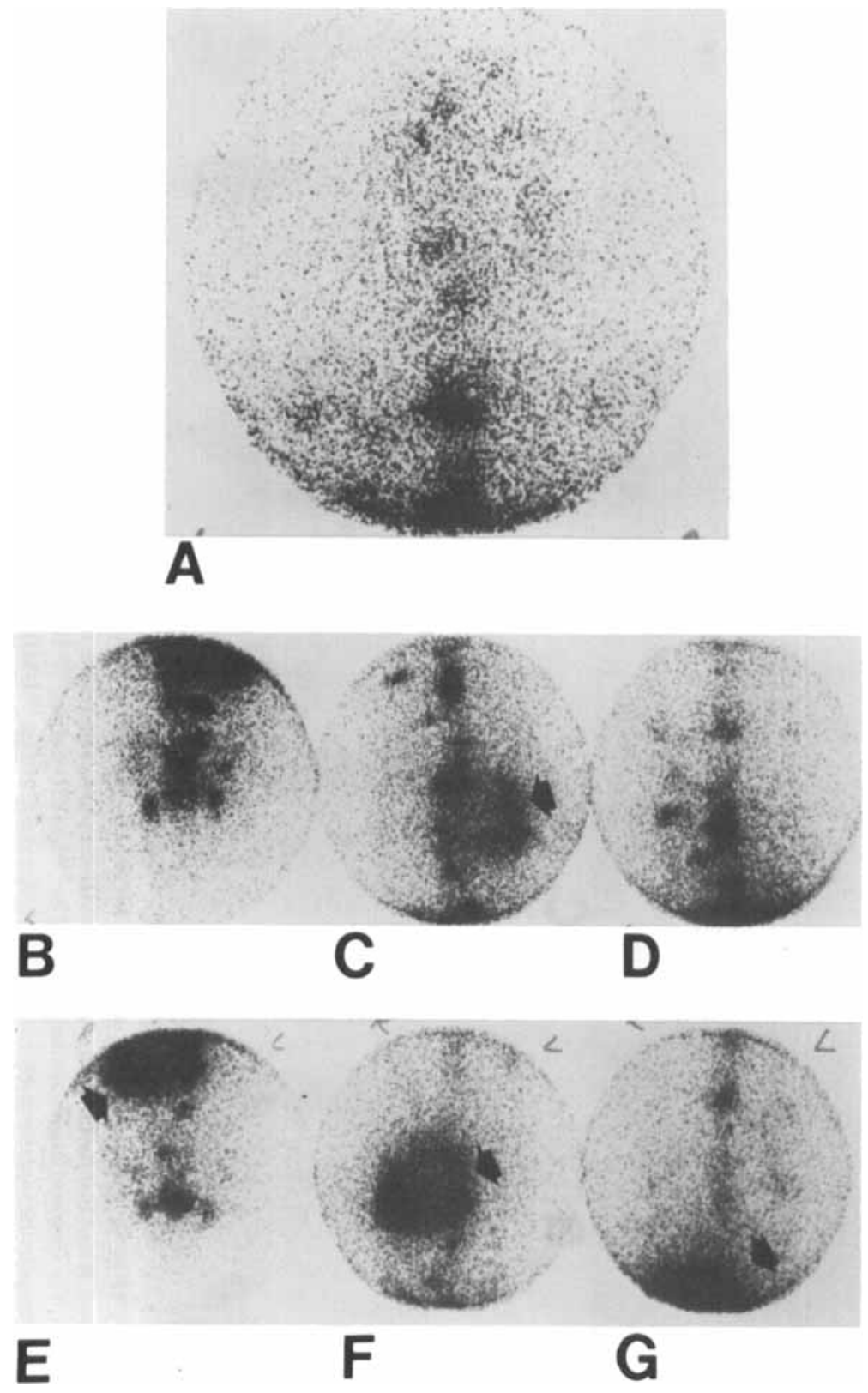

Fig. 1. Extensive skeletal metastases demonstrated by ${ }^{131}$ I-MIBG scintigraphy. A, Anterior head and neck; B, posterior pelvis; C, posterior abdomen; D, posterior chest; E, anterior pelvis; F, anterior abdomen; $G$, anterior chest. Solid arrow indicates large right adrenal primary with necrotic center manifesting as a 'halo' sign. 

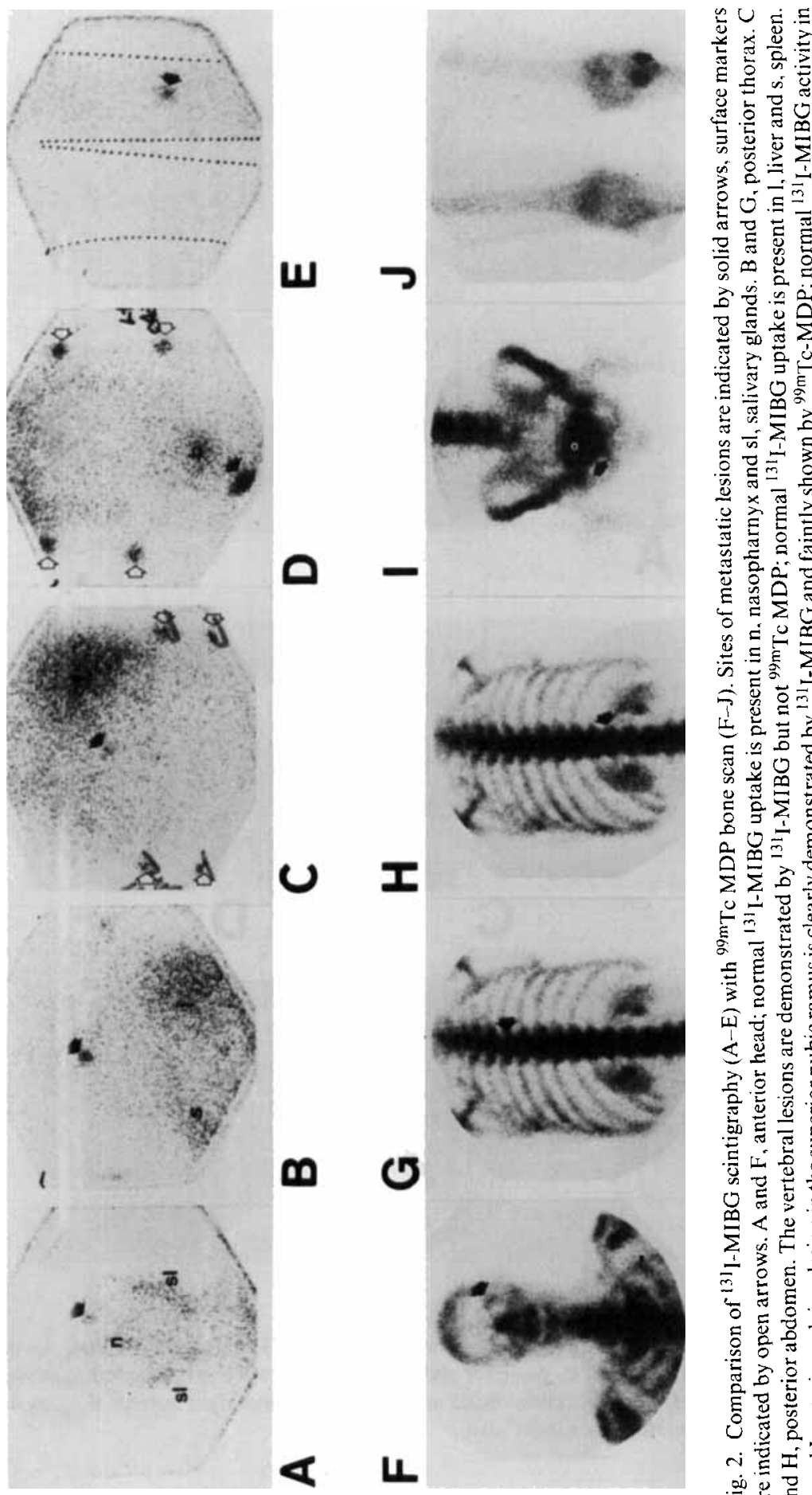

ते 穷

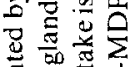
롤월 管

$5: 3$

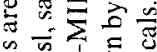

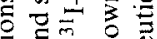
标的 关芯总 要焉要 递它过

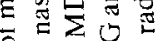
○延泀 污实焉 司至立

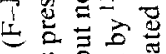
漹 岙氜 苍突要 을 氖 $\sum \sum \overrightarrow{0}$ 比焉焉

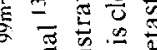
吉导总

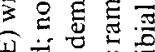

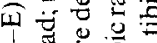

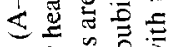
롱ㅎㅎㅎㅎㅇ 言总总总 些焉要要

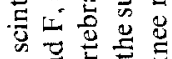
$0 \mathscr{E}_{\vec{D}}$

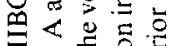

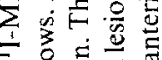
ॠ 过

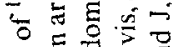
區五要

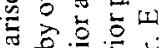
总司高

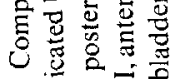

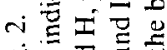

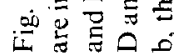



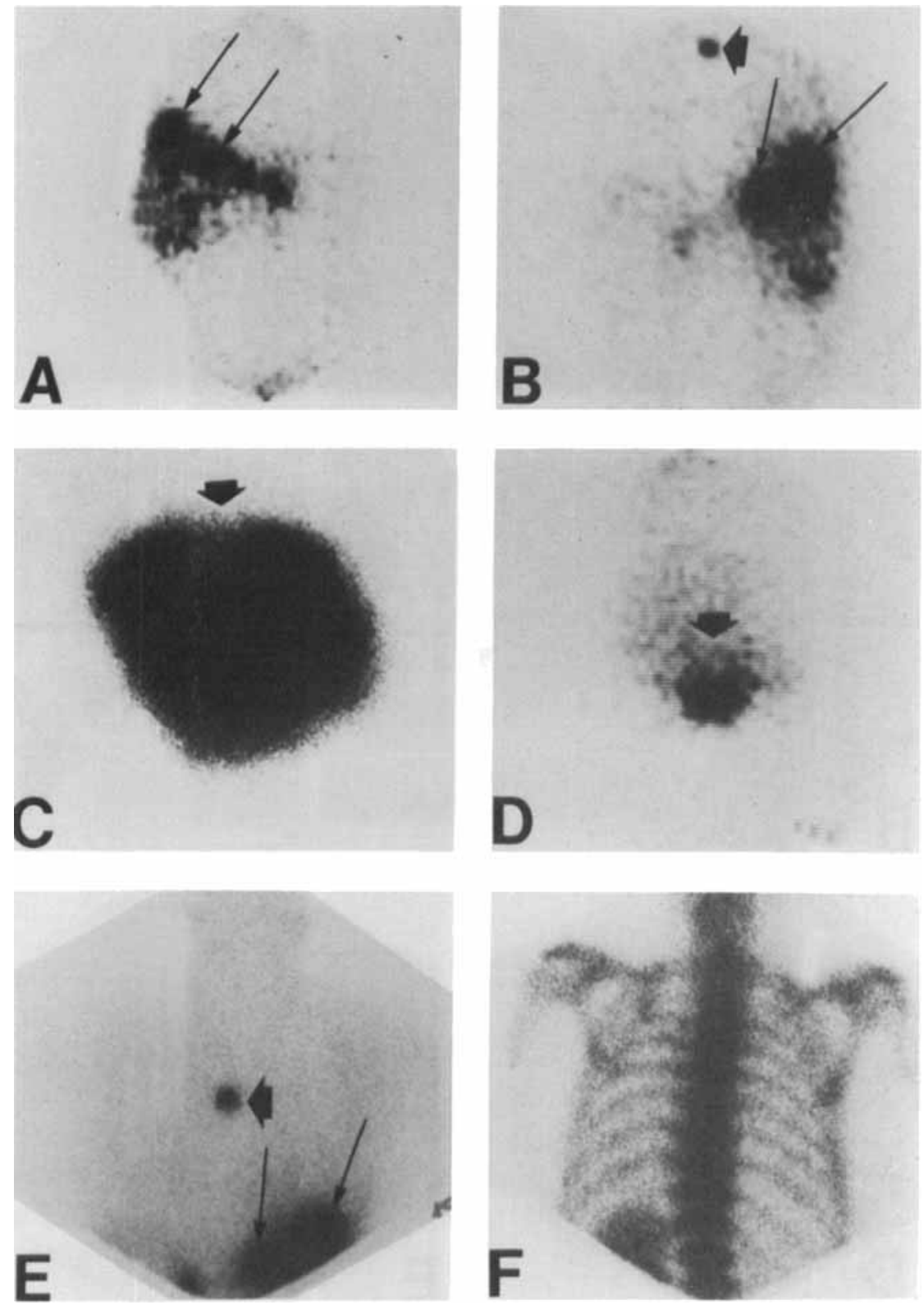

Fig. 3. Hepatic metastases and single vertebral metastases. A, Anterior abdomen; B, posterior abdomen, normal hepatic concentration of ${ }^{131} \mathrm{I}-\mathrm{MIBG}$ with areas of supernormal concentration at the sites of metastases (small arrows), a single midthoracic abnormal focus is indicated by the large arrow. C, Right lateral ${ }^{99 \mathrm{~m}} \mathrm{Tc}$ sulphur colloid liver scan demonstrating a defect (arrow) due to metastases, other views were normal. D, Right lateral ${ }^{131}$ I-MIBG showing increased tracer uptake (arrow) which corresponds to the defect seen on the liver scan. E, posterior chest image with ${ }^{131}$ I-MIBG, hepatic metastases indicated by small arrows, vertebral lesion indicated by large arrow. F, posterior chest image with ${ }^{99} \mathrm{~m}$ Tc-MDP and demonstrates no obvious skeletal abnormality. 

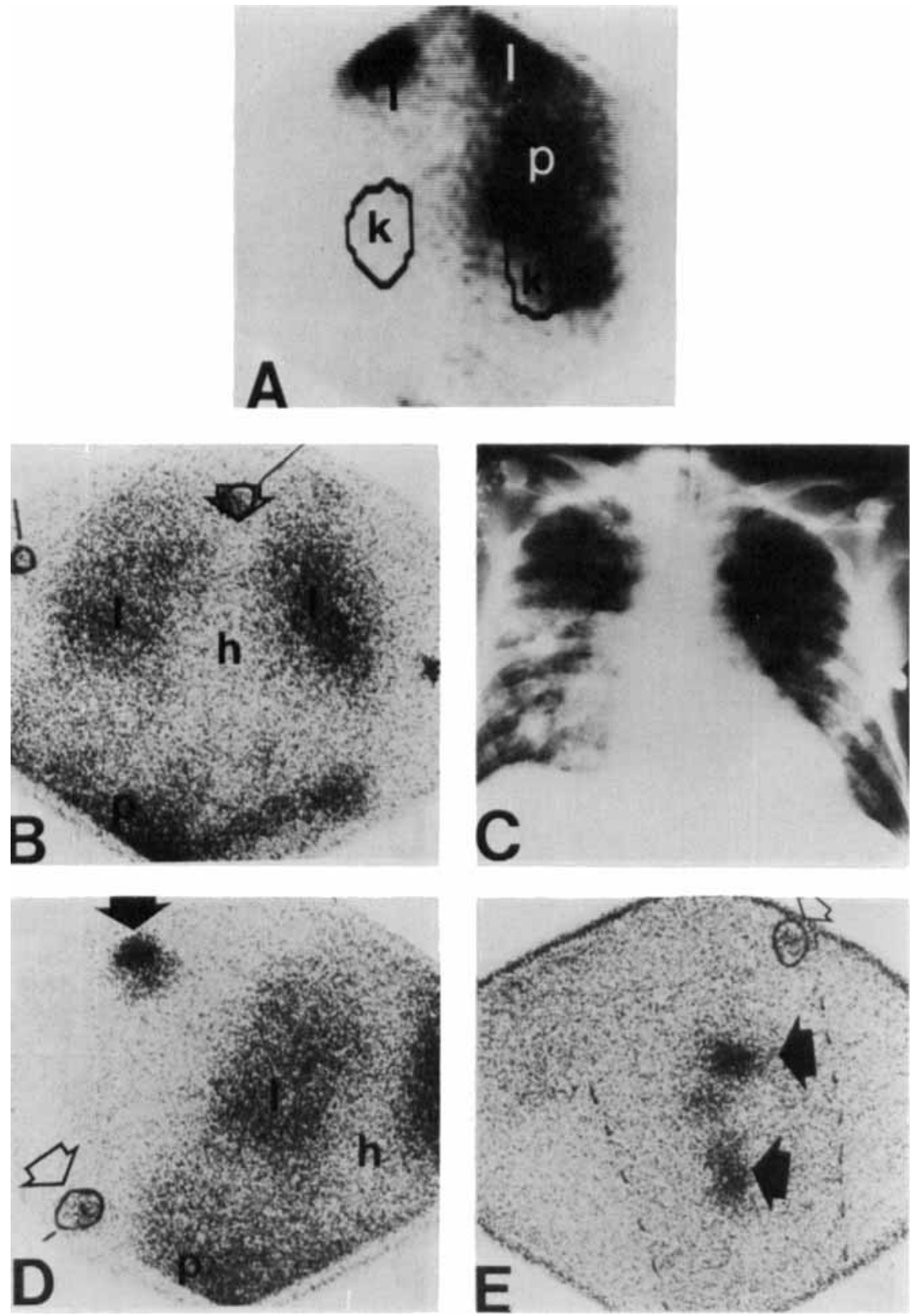

Fig. 4. Pulmonary and skeletal metastases with large right adrenal primary. A, Posterior abdomen ${ }^{131}$ I-MIBG image demonstrating $\mathbf{p}$, a large right adrenal primary tumour, and I, pulmonary uptake; $k$, the sites of the kidneys are demonstrated by the outlines taken from a simultaneous ${ }^{99 \mathrm{~m}} \mathrm{TC}-\mathrm{DPTA}$ renal scan. $\mathrm{B}$ and $\mathrm{C}$. posterior chest ${ }^{131} \mathrm{I}-\mathrm{MIBG}$ image and corresponding chest $\mathrm{x}$-ray demonstrating $\mathrm{l}$, extensive bilateral pulmonary uptake, and $\mathrm{p}$, primary tumour. $h$ is the region of the heart: and the open arrow indicates a marker in the suprasternal notch. D, an anterior shoulder and chest image. demonstrating abnormal uptake of ${ }^{131}$ I-MIBG in the humeral head (solid arrow). 1 . lung, and p, right adrenal region; the open arrow indicates a marker on the costal margin. E. anterior left thigh with abnormal ${ }^{131}$ I-MIBG uptake in a pathological fracture (solid arrows), the open arrow indicates a marker on the greater trochanter. 
Table 2. Frequency of clinical manifestations

\begin{tabular}{lcc}
\hline & At initial diagnosis & At time of ${ }^{131}$ I-MIBG scan \\
\hline $\begin{array}{l}\text { Catecholamine effects } \\
\quad \text { Sustained } \\
\text { hypertension* }\end{array}$ & $29 / 30$ & $27 / 30$ \\
Paroxysmal & & \\
hypertension* & $12 / 30$ & $5 / 30$ \\
'Spells' & & \\
Hyperglycaemia & $20 / 30$ & $11 / 30$ \\
Vomiting & $9 / 30$ & $7 / 30$ \\
Diarrhoea & $2 / 30 \ddagger$ & $0 / 30$ \\
Local tumour effects & $1 / 30$ & $1 / 30$ \\
Abdominal mass or pain & & \\
Bone pain & $5 / 30$ & $2 / 30$ \\
Respiratory & $8 / 30$ & $7 / 30$ \\
distress & $1 / 30 \dagger$ & $2 / 30$ \\
Noncatecholamine & & \\
humoral effects & & \\
Polycythaemia & & \\
Hypercalcaemia & $1 / 30$ & $2 / 30$ \\
Weight loss & $2 / 30$ & $3 / 30$ \\
Other & $8 / 30$ & \\
Asymptomatic & & $3 / 30$ \\
\hline
\end{tabular}

* Sustained hypertension and paroxysmal hypertension frequently coexisted. $\dagger$ Extensive pulmonary metastases. $\ddagger$ Both children.

Widespread pulmonary metastases were well demonstrated by ${ }^{131}$ I-MIBG (Fig. 4) scintigraphy in two patients but only faintly in another where they were known to be present. Neither ${ }^{131}$ I-MIBG scintigraphy, which detected larger peritoneal tumour deposits, nor $\mathrm{CT}$, demonstrated small peritoneal seedlings in a patient which were only revealed at laparotomy.

The clinical features of phaeochromocytoma at the time of original diagnosis and of ${ }^{131}$ I-MIBG scintigraphy showed no correlation with the extent of tumour spread (Table 2). At the time of ${ }^{13 i}$ I-MIBG scintigraphy all but three patients were receiving therapy, mostly adrenergic receptor blocking agents, for control of hormone-provoked symptoms. These medications ameloriated symptoms in most cases (Table 2), but did not appear to influence the uptake of ${ }^{13}$ I-MIBG by tumour. Symptoms arose principally from the effects of catecholamine excess or to a lesser extent local tumour masses.

\section{DISCUSSION}

\section{Morphology}

Each of our 30 patients fulfilled the criteria for malignancy. Although no histological criteria are totally specific for malignancy, features such as mitotic figures, pleomorphism, necrosis and capsular or vascular invasion occurred frequently in the cases studied and we 
have found some of these features including necrosis, mitoses and vascular invasion, to be rare in phaeochromocytomas which follow a benigh course. No histological feature predicted the anatomical extent of tumour spread, ${ }^{131}$ I-MIBG uptake nor patterns of plasma catecholamine concentrations or urinary catecholamine excretion rates. A zellballen pattern was more prominent in the extra-adrenal tumours than in the intra-adrenal phacochromocytomas.

\section{Demographic features}

The occurrence of malignancy in 30 of 70 cases of phaeochromocytoma studied is higher than reported by others (Palmieri et al., 1961; Sander et al., 1971; Mahoney \& Harrison, 1977; Modlin et al., 1979). The age of onset too, was lower than in most series, with 11 of 30 cases developing in the paediatric age group. The rarity of malignant phaeochromocytoma in childhood has been emphasized by certain authors (Stackpole et al., 1973; Lorenzo, 1977; Quissel et al., 1979). These variations from previously published experience, probably reflect the bias in the referral patterns rather than the true frequency of malignancy and childhood onset. Patients were referred for scintigraphy when the extent of malignancy or nature of phaeochromocytoma was in question. Our results, however, may indicate that malignant phaeochromocytoma developing in childhood is more common than previously believed. Malignant phaeochromocytomas presenting in childhood seem to manifest a more indolent course than that seen in older patients (Stackpole et al., 1973; Mahoney \& Harrison, 1977; Shapiro et al., 1982a), and lacking pathognomonic morphology of malignancy may for years appear to be benign.

The preponderance of males ( 21 of 30 cases) contrasts with the equal sex distribution in most series (Palmieri et al., 1961; Scott et al., 1982) or female preponderance in others (Wust Van et al., 1964; Sander et al., 1971; Mahoney \& Harrison, 1977). Reports of paediatric patients also describe a higher frequency in females (Quissel et al., 1979).

In only two of our patients was there unequivocal evidence of a neurocristopathic syndrome known to be associated with phaeochromocytoma (Quissel et al., 1979; Sizemore et al., 1980; Riccardi, 1981). This reflects the small percentage of phaeochromocytomas due to these syndromes as well as the rarity of malignant change in adrenergic tumours of the familial type.

Since the vast majority of phaeochromocytomas arise from one or both adrenal glands, our finding that 13 of 30 malignant tumours arose in extra-adrenal sites confirms the observation that extra-adrenal phaeochromocytomas are more likely to be malignant (Schonebe, 1969; Glenn \& Gray, 1976; Shapiro et al., 1982a). This observation held for tumours arising in both adults and children (Lorenzo, 1977; Quissel et al., 1979).

\section{Functional indices}

\section{Noncatecholamine humoral effects}

Phaeochromocytomas have been associated with a number of para-neoplastic syndromes not explicable on the basis of elevated catecholamine levels. These include polycythaemia, hyperthermia and hypercalcaemia in the absence of hyperparathyroidism (Symington \& Goodall, 1953; Waldmann \& Bradley, 1961; Sjoerdsma et al., 1966; Shimbu \& Makamo, 1974). True polycythaemia with increased red cell mass appears to have been a result of an erythropoietic-stimulating factor produced by the tumour (Waldmann \& Bradley, 1961) 
and may resolve following extirpation. This condition must be distinguished from the apparent polycythaemia due to a contraction of plasma volume (in the absence of an expanded red cell mass) that may occur in untreated phaeochromocytoma (Sjoerdsma et al., 1966) and from coincidental polycythaemia vera or secondary polycythaemia. One patient exhibited polycythaemia induced by the synthesis of erythropoietin by his malignant phaeochromocytoma with a markedly elevated haematocrit, a proportionally increased red cell mass, no evidence of leukocytosis or thrombocytosis, neither an abnormal haemoglobin nor hypoxia, and high levels of circulating immunoreactive erythropoietin. Urfortunately, due to the wide dissemination of his tumour, the phenomenon of regression following extirpation could not be demonstrated.

\section{Abnormalities of catecholamines}

Under normal circumstances, the conversion of noradrenaline to adrenaline requires the enzyme phenylethanolamine- $n$-methyltransferase and very high levels of cortisol, a combination present only in the adrenal medulla (Axelrod, 1962). It is possible that in the face of very high noradrenaline concentrations a small amount of conversion to adrenaline may occur via extra-adrenal phenylethanolamine- $n$-methyltransferases (Buu et al., 1981; Kopp et al., 1978; Von Euler et al., 1961). The same principle could hold for the tumours themselves. The elevated levels of adrenaline were not artefacts as they were substantiated by the assay of serial dilutions. However, whatever the source, patients did not exhibit adrenaline-type symptoms, all hormonally mediated symptoms and signs could be attributed to noradrenaline alone (with the exception of erythropoietin in one patient and hypercalcaemia in two others). The effects of malignant phaeochromocytoma are then the consequences of the local effects of tumour masses and/or of the elevated levels of circulating noradrenaline. Considerable variation in excretion patterns of the catecholamines and the catecholamine metabolites was observed, and these patterns were sometimes discrepant with plasma catecholamine concentrations reflecting differing rates of metabolism for the hormones. Thus, despite the experience of others who have found superior diagnostic precision with either technique alone (Crout et al., 1961; Sjoerdsma et al., 1966; Bravo et al., 1979), we advise the measurement of all components of plasma and urine.

\section{${ }^{13 !}$ I-MIBG uptake}

The mechanism of ${ }^{131}$ I-MIBG uptake into adrenergic tissues (including malignant phaeochromocytoma) is believed to involve the active transport of ${ }^{131} \mathrm{I}-\mathrm{MIBG}$ via the noradrenaline 're-uptake' mechanism (Sisson et al., 1981; Wieland et al., 1980, 1981). The efficiency of this mechanism and hence the storage of ${ }^{131} \mathrm{I}-\mathrm{MIBG}$ in vesicles need not necessarily parallel that of catecholamine synthesis, and indeed the wide spectrum of scintigraphic intensity by different lesions supports this concept. However, the reasons for the disparity of uptakes of ${ }^{131}$ I-MIBG by the tumours of different patients and by different lesions within the same patient are at present unknown. However, in four patients major sites of skeletal metastases had been subjected to external beam irradiation before ${ }^{131}$ I-MIBG scintigraphy and showed slight to no uptake. Such therapy may have affected the ability of the lesions to take up ${ }^{131}$ I-MIBG without halting catecholamine synthesis or causing tumour regression.

Since scintigraphy can usually demonstrate primary malignant phaeochromocytomas, recurrent tumours and most metastases, the imaging technique not only helps to define 
the extent of dissemination of known malignant disease, but also detects the malignant nature of what otherwise may be thought to be a benign phaeochromocytoma ( 4 of 30 in this series). Scintigraphy has the advantage of providing a noninvasive procedure that readily screens the whole body, and in many cases ( 16 of 30 ), it is more sensitive for phaeochromocytoma than $\mathrm{CT}$, conventional radiography of bone scan. Focal uptake of ${ }_{131}$ I-MIBG has been specific for phaeochromocytoma (one false positive in 270 cascs studied, this being a patient with a large retroperitoneal neuroendocrine tumour which concentrated ${ }^{131}$ I-MIBG but manifested no evidence of catecholamine hypersecretion), but the false negative rate has been about $7-10 \%$ (Shapiro et al., 1982a, b).

\section{Anatomical spread of tumour}

The extent and pattern of spread of the principle lesions in the present series is typical, with the skeleton, liver, regional lymph nodes, lung and peritoneum affected in that order of frequency (Palmieri et al., 1961; Wust Van et al., 1964; McCarthy et al., 1977; Quissel et al., 1979) (see Table 1). Other rarer sites of spread such as brain (Ferrari et al., 1979), skin (Cato et al., 1967), pleura (Traub \& Rosenfeld, 1970) and distant lymph nodes (Sandritter $\&$ Lasch, 1967) were not observed. The finding of skeletal metastases in 20 of 30 cases was in keeping with other series which have reported bone to be the commonest site for metastases (Schonebe, 1969; McCarthy et al., 1977) and occasionally the only side (Stackpole et al., 1973; McCarthy et al., 1977). In many cases skeletal metastases showed high ${ }^{13.1}$ I-MIBG uptake.

Four of 20 patients had liver deposits, another frequently recorded site of metastasis (Palmieriet al., 1961; Wust Van et al., 1964).

While hepatic uptake of ${ }^{131}$ I-MIBG is a normal finding in scintigraphy, the radiopharmaceutical disappears from this organ for the most part in $48 \mathrm{~h}$. The relatively poor uptake of the tracer by hepatic metastases when compared to that seen in skeletal metastases is not due to the relatively high liver background but may reflect the influence of the host tissue on ${ }^{131}$ I-MIBG uptake by the tumour.

\section{Clinical course and therapy}

Others authors have recorded varying courses for malignant phaeochromocytoma with survival varying from months to decades (Palmieri et al., 1961; James et al., 1972; Mahoney \& Harrison, 1977; Modlin et al., 1979; Das \& Lowe, 1980). At present, 27 of the 30 patients are alive and 24 are fully functional although two patients have spinal cord compression with neurological deficits. Prolonged survival (up to decades) with widely metastatic phaeochromocytoma is not uncommon (Traub \& Rosenfeld, 1970; James et al., 1972; Scharf et al., 1973; Vanden Broek \& DeGraeff, 1978; Scott et al., 1982), but our study population appears to have a disproportionate number of such cases. No obvious differences in the clinical presentations distinguish patients with the slowly and the rapidly progressive diseases (Mahoney \& Harrison, 1977). Pathological fractures were seen in slowly advancing tumours as well as with rapidly progressive and fatal disease. Many patients with pulmonary metastases survive only a year or two (VandenBroek \& DeGraeff, 1978; Abemayor et al., 1980) a course borne by one patient in this series, but exceptions occur (VandenBroek \& DeGraeff, 1978; Quissel et al., 1979; Abemayor et al., 1980).

The treatment of malignant phaeochromocytoma is unsatisfactory. The most impor- 
tant component is the use of blocking agents which block the effects of secretory products from the tumour (Boreus et al., 1968). Such therapy, while not affecting tumour progression, may prevent life-threatening cardiovascular effects and permit prolonged survival and good quality of life despite widely disseminated tumours (Boreus et al., 1968; Scharf et al., 1973). Catecholamine synthesis may be diminished by the administration of alphamethylparatyrosine. This drug seldom reduces catecholamines to completely normal levels, but may provide adequate control of hormonal effects when used alone or it may permit the reduction in the dose of adrenergic blocking agents (Sjoerdsma et al., 1965; Tchergakoff et al., 1972).

Locally invasive tumours may be cured by radical extirpation (Schonebe, 1969; Mahoney \& Harrison, 1977; Drasin, 1978; Modlin et al., 1979; Das \& Lowe, 1980). Many patients may have long disease free intervals (up to decades) following initial surgery. Even when distant metastases have occurred, surgical excision of isolated lesions has been of benefit because of the reduction in catecholamine levels and removal of mass effects of lesions (McCarthy et al., 1977; Vanden Broek \& DeGraeff, 1978; Abemayor et al., 1980). Multiple resections may be required (VandenBroek \& DeGraeff, 1978). Skeletal lesions may benefit from external beam irradiation while other sites are less responsive (James $e t$ al., 1972; Drasin, 1978). The role of chemotherapy is debatable but responses to doxorubicin and cyclophosphamide have been reported (Joseph, 1967; Drasin, 1978). All studies on the effects of irradiation and/or chemotherapy are hindered by the rarity and the variability in the natural history of this disease.

The affinity of the radiopharmaceutical, ${ }^{131} \mathrm{I}-\mathrm{MIBG}$, for many malignant phaeochromocytomas raises the possibility that benefit may occur from the administration of large doses of the radiopharmaceutical, a study now underway (Sisson et al., 1983).

\section{ACK NOWLEDGEMENTS}

We would like to thank all the physicians who referred patients, Ms Joanne Boldt for typing the manuscript, Ms Jeanne Copp for data management, Dr V. DeQuattro for the measurement of plasma normetanephrine, Dr T. Mangner and Holley Anderson-Davis for synthesis of ${ }^{131}$ I-MIBG and the Phoenix Memorial Laboratory for the use of radiochemical facilities. This study was supported by grants from the American Cancer Society (PDT 182), the National Cancer Institute (NC15 T32 CA09015), The National Institute of Arthritis, Metabolism and Digestive Diseases (5R01AM21477), DHEW (3M01 RR00042-22 S1 CLR) and by the Nuclear Medicine Research Fund. B.S. is a recipient of a National Institutes of Health Clinical Associate Physician Award (DHEW 3M01 RR00042-22 S1 CLR).

\section{REFERENCES}

Abemayor, E., Halken, A.H. \& Copp, C.E. (1980) Multiple sequential pulmonary resections for metastatic pheochromocytoma with long-term survival. American Journal of Surgery, 140, 696-697.

Axelrod, J. (1962) Purification and properties of phenyl ethanolamine- $n$-methyltransferase. Journal of Biological Chemistry, 237, 1657-1660.

Bartles, E.C. (1959) Malignant pheochromocytoma. Surgical Clinics of North America, 39, 805-808.

Boreus, L.O., Broberger, U., Negardh, A. \& Zetterqvist, P. (1968) Malignant pheochromocytoma in a child; treatment with a combination of alpha and beta adrenergic blockade. Acta Pediatrica Scandinavica, $57,36-40$.

Bravo, E.L., Tarazi, R.C., GifFord, R.W.\& Stewart, B.H. (1979) Circulating and urinary catecholamines in 
pheochromocytoma: Diagnostic and pathophysiologic implications. New England Journal of Medicine, $301,682-686$.

BuU, N.T. NAIK. G., KuCHEL, O. \& GENEST, J. (1981) The extra-adrenal synthesis of epinephrine in rats: Possible involvement of dopamine sulfate. Journal of Laboratory and Clinical Medicine, 98, 527-535.

Cato, T. Hirakawa, T. \& Shimada, T. (1967) A necropsied case of pheochromocytoma metastasized to skin and other organs. Acta Urologica Japonica. 13, 443-445.

Crout, J.R., Pisano, J.J. \& Sjoerdsma, A. (1961) Urinary excretion of catecholamines and metabolites in pheochromocytoma. American Heart Joumal, 61, 375-381.

DAS, S. \& Lowe, P. (1980) Malignant pheochromocytoma of the bladder. Journal of Urology, 123, $282-284$.

Drasin, H. (1978) Treatment of a malignant pheochromocytoma. Western Journal of Medicine, 128, $106-111$.

Ferrari, G., Togni, R.. Pizzedaz, C. \& Aldovini, D. (1979) Cerebral metastases in pheochromocytoma. Pathologica, 71, 703-710.

Gitlow, S.E., Mendlowitz, M. \& Vertani. L.M. (1970) The biochemical techniques for detecting and establishing the presence of a pheochromocytoma: A review of ten years' experience. American Journal of Cardiology, 26, 270-279.

Glenn. F. \& Gray. G.F. (1976) Functional tumours of the organ of Zuckerkandl. Annals of Surgery, 9, 578-582.

JAMES, R.E., BAKER. H.L. \& SCANLON, P.W. (1972) The roentgenologic aspects of metastatic pheochromocytoma. American Journal of Roentgenology, 115, 783-793.

JoSEPH, L. (1967) Malignant phaeochromocytoma of the organ of Zuckerkandl with functioning metastases. British Journal of Urology, 39, 221-225.

Kopp, N., Denoroy, L., Renaud, B.. Pujol. J.F., Gay, N. \& Tommasi, M. (1978) Adrenaline synthesizing enzyme distribution in human brain. In Catecholamines: Basic and Clinical Frontiers. Proceedings of the Fourth International Catecholamine Simposium, Pacific Grove California, September 17-22, 1978 (eds E. Usvine, I. C. Kopin \& J. Burchas), Vol. 1, pp. 171-173. Pergamon Press, New York.

Kvale, W.F., Roth, G.M.. Manger. W.M. \& Priestly, J.T. (1956) Pheochromocytoma. Circulation, 14, 622-630.

Lorenzo, R.L. (1977) Malignant recurrent extra-adrenal pheochromocytoma in a child. Pediatric Radiology, 5, 175-177.

MAHONeY, E.M. \& HaRRISON, J.H. (1977) Malignant pheochromocytoma: Clinical course and treatment. Journal of Urology, 118, 225-229.

MANGER, W.M. \& GiFFORD, R.W. (1982) Hypertension secondary to pheochromocytoma. Bulletin of the New York Academ. of Medicine. 58, 139-158.

MCCarthy, E.F.. Bonfiglio, M. \& Lawton. W. (1977) A solitary-functioning osseous metastasis from a malignant pheochromocytoma of the organ of Zuckerkandl. Cancer, 40, 3092-3096.

Minnow, A.M., Bennett, W.A. \& Kvale, W.F. (1954) Pheochromocytoma: A study of 15 cases diagnosed at autopsy. New England Journal of Medicine, 251, 959-956.

Modlin, I.N., Farndon, J.R., ShePherd, A., Jonston, I.D.A., Kennedy, P.C., Montgomery, D.A.D. \& WelbourN, R.B. (1979) Phaeochromocytomas in 72 patients: Clinical and diagnostic features, treatment and long-term results. British Journal of Surgery, 66, 456-465.

Palmieri, G.. IkKos, D. \& LufT, R. (1961) Malignant phaeochromocytoma. Acta Endocrinologica (Copenh), 36, $549-560$.

Peulfr. J.D. \& JOHNSon, G.A. (1977) Simultaneous single isotope radioenzymatic assay of plasma norepinephrine, epinephrine and dopamine. Life Sciences, 21, 625 632.

Quissel. B.. Mohammad, A.. Bauer. J.H. \& Hakam, N. (1979) Malignant pheochromocytoma in childhood: Report of a case with familial neurofibromatosis. Medical and Pediatric Oncology, 7, 327-333.

RicCARDI, V.N. (1981) Von Recklinghausen neurofibromatosis. New England Journal of Medicine, 305, $1617-1626$.

Sander, S., Muri, O. \& Mathisen, W. (1971) Phaeochromocytoma: A follow-up study of 21 patients. Acta Chirugica Scandinaria, 137, 470473

SANDritter, W. \& Lasch, H.G. (1967) Phaochromozytom-malignes. Phaochromozytom Medizinische Welt, 18, 113-117.

Scharf, Y., Nahir. A.N., Better, O.S., Koten, A., Benarich, Y. \& Gellei, N. (1973) Prolonged survival in malignant pheochromocytoma of the organ of Zuckerkandl with pharmacological treatment. Cancer, 31, 746-750. 
SCHONEBE, C.K. (1969) Malignant phaeochromocytoma. Scandinavian Journal of Urology and Nephrology, 3, 64-68.

Scott, W.H., Reynolds, V., Green, N., Page, D., Oates, J.A., Robertson, D. \& Roberts, S. (1982) Clinical experience with malignant pheochromocytoma. Surgery Gynecology and Obstetrics, 154, 801-818.

SHAPIRO, B., Sisson, J.C. \& BeIERWALTES, W.H. (1982a) Experience with the use of ${ }^{131}$ I-metaiodobenzylguanidine for locating pheochromocytomas. Nuclear Medicine and Biology Proceedings of the Third World Congress of Nuclear Medicine and Biology, Paris, August 29-September 2. (ed C. Raynaud), Vol. II, pp. 1265-1268. Pergamon Press, Paris.

Shapiro, B., Sisson, J.C. \& BeierWaltes, W.H. (1982b) Functional imaging of malignant pheochromocytoma by ${ }^{131}$ I-metaiodobenzylguanidine scintigraphy. Clinical Research, 30, 554A (Abstract).

ShimbU, S. \& MaKAMO, Y. (1974) A case of malignant pheochromocytoma producing parathyroid hormone-like substance. Calcified Tissue Research, 15, 155-156.

Sisson, J.C., Frager, M.S., Valk, T.W., Gross, M.D., Swanson, D.P., Wieland, D.M., Tobes, M.C., Beierwaltes, W.H. \& Thompson, N.W. (1981) Scintigraphic localization of pheochromocytoma. New England Journal of Medicine, 305, 12-17.

Sisson, J.C., Shapiro, B., Beierwaltes, W.H., Satterlee, W.G., Nakajo, M., Glowniak, J.V., Mangner, T.J., Carey, J.E., Swanson, D.P., Copp, J.E. \& Wieland, D.M. (1983) Treatment of malignant pheochromocytomas with a new radiopharmaceutical. Clinical Research, 31, 547A (abstract).

SIZEMORE, G.W., HEATH, H. \& CARNEY, J.A. (1980) Multiple endocrine neoplasia type 2. Clinical Endocrinology and Metabolism, 9, 299-315.

SJoerdsma, A., Engelman, K., SPeCtor, S. \& Undenfriend, S. (1965) Inhibition of catecholamine synthesis in man with alpha-methyl-tyrosine, an inhibitor of tyrosine hydroxylase. Lancet, ii, 1092-1094.

Suofrdsma, A., Engelman, K., Waldmann, T.A., Copperman, L.H.\& Hammond W.G. (1966) Pheochromocytoma: Current concepts of diagnosis and treatment. Annals of Internal Medicine, 65, 1302-1326.

Stack Pole, R.H., Melicow, M.H. \& Uson, A.C. (1973) Pheochromocytoma in children. Journal of Pediatrics, 63, 315-330.

Symington, T.H. \& Goodall, A.L. (1953) Studies in pheochromcytoma: I. Pathological aspects. Glasgow Medical Journal, 34, 75-121.

Tchergakoff, P.H., Menard, J., Bedrossian, J., Vaysse, J., Alexandre, J.M. \& Milliev, P. (1972) Pheochromocytome malin metastase traitement par le alpha-methyl-para-tyrosine. Semaine Des Hopitaux de Paris, 48, 1779-1787.

TRAUB, U.M. \& RosenfeLD, J.B. (1970) Malignant pheochromocytoma with pleural metastases of unusually long duration. Chest, 58, 546-550.

VandenBroek, P.J. \& DeGraeff, J. (1978) Prolonged survival in a patient with pulmonary metastases of a malignant phaeochromocytoma. Netherlands Journal of Medicine, 21, 245-247.

VON EULER, U.S., IKKos, D. \& LuFT, R. (1961) Adrenaline excretion during resting conditions and after insulin in adrenalectomized human subject. Acta Endocrinologica (Copenh), 38, 441-448.

Von Euler, U.S. \& Lishajko, S. (1959) The estimation of catecholamines in urine. Acta Physiologica Scandinavia, 45, 122-132.

VON SCHLEGLE, G.G. (1960) Neurofibromatose Recklinghausen und Phaochromocytom. Schweizerische Medizinische Wochenschrift, 90, 31-39.

Waldmann, T.A. \& BRadLey, J.E. (1961) Polycythemia secondary to pheochromocytoma with the production with an erythropoiesis-stimulating factor by the tumour. Proceedings of the Society for Experimental Biology and Medicine, 108, 425-427.

Wieland, D.M., Brown, L.E., Tobes, M.C., Rogers, W.L., Marsh, D.D., Mangner, T.J., Swanson, D.P. \& BEIER WALTES, W.H. (1981) Imaging the primate adrenal medulla with $\left[{ }^{123} \mathrm{I}\right]$ and $\left[{ }^{131} \mathrm{I}\right]$ metaiodobenzylguanidine. Journal of Nuclear Medicine, 22, 358-364.

Wieland, D.M., Wu, J.I., Brown, L.E., Mangner, T.J., Swanson, D.P. \& Beierwaltes, W.H. (1980) Radiolabeled adrenergic neuron blocking agents: Adrenal medullary imaging with $\left[{ }^{131} \mathrm{I}\right]$-iodobenzylguanidine. Journal of Nuclear Medicine, 21, 349-353.

Wust VAN, G., KlUGE, A. \& BarKofF (1964) Zur clinic und morphologie maligna tumoren des chromaffin systems. Oncologia, 18, 101-119. 